\title{
A woman with forgetfulness and falls
}

\author{
Louise Pealing general practitioner, Steve lliffe professor of primary care for older people
}

Research Department of Primary Care and Population Health, Royal Free Hospital, London NW3 2PF, UK

\begin{abstract}
A 69 year old woman presented to her general practitioner with a six month history of occasional falls and fluctuating forgetfulness and attention. Although she reported no difficulties with names and dates she needed help with taking drugs and preparing meals. She had also had two episodes of apparent visual hallucinations of a woman standing at the foot of her bed. Her sleep behaviour had been poor for many years, with frequent strong physical jerks and motion while sleeping. She had no symptoms of altered or low mood. Her medical history included hypothyroidism, osteoporosis, and cholesteatoma, and she was being investigated for a mixed fibre peripheral sensory neuropathy of unknown cause. Current drugs included levothyroxine, calcitriol, calcium carbonate-colecalciferol, and lansoprazole. She did not drink alcohol and was a non-smoker. On examination she was fully orientated in time and place and her AMTS (abbreviated mental test score) was $10 / 10$ with an MMSE (mini-mental state examination) score of 26/30. Her blood pressure, temperature, and cardiovascular and respiratory examinations were normal. Cranial nerve examination was normal with no primitive reflexes or supranuclear gaze palsy. Tone and power were normal throughout all limbs, as were sensation and reflexes in the upper limbs. The lower limbs showed reduced vibration and pin prick sensation to the mid-shin bilaterally, and joint position sense was limited to large movements. She showed no evidence of bradykinesia or apraxia, but her gait was ataxic in keeping with her peripheral sensory impairment.
\end{abstract}

\section{Questions}

1 What is the differential diagnosis?

2 What investigations would you do?

3 How should this patient be managed?

\section{Answers}

\section{What is the differential diagnosis? Short answer}

Given the patient's fluctuating forgetfulness and alertness, the differential diagnosis must include causes of delirium and dementia. The most common causes of delirium in this age group are infection, metabolic and nutritional disturbances (including hypoxia and hypoglycaemia), cerebral haematomas caused by trauma, intoxication, endocrinopathies (including thyroid and parathyroid disorders), space occupying lesions, and side effects or interactions of drugs. The syndrome of dementia has four main types: Alzheimer's disease, vascular dementia, dementia with Lewy bodies, and frontotemporal dementia. A corroborative history from a family member or carer is essential when making a diagnosis. ${ }^{1}$

\section{Long answer}

To differentiate between delirium or dementia as causes of our patient's symptoms, it is important to clarify whether the onset of symptoms was gradual, acute, or fluctuating. These two syndromes can also be distinguished between on the basis of changes in consciousness, attention, and psychomotor activity, all of which tend to be disturbed or fluctuating in delirium but minimally affected in dementia, ${ }^{2}$ although they are common in dementia with Lewy bodies. The simple CAM tool (confusion assessment method) can be used to screen for delirium and is easily administered within a general practice consultation, although it also needs a supporting history. ${ }^{3}$ The tool identifies an acute onset and fluctuating course, inattention, disorganised thinking, and an altered level of consciousness. A diagnosis of delirium requires the first two criteria and either the third or fourth. The diagnosis is complicated by the strongest risk factor for delirium being dementia, with a fivefold increase in risk of delirium in patients with dementia. ${ }^{4}$

Common infective causes of delirium in older people include pneumonia and urinary tract infection, ${ }^{5}$ which can present atypically in older people. ${ }^{6}$ Fluctuating cognitive effects can be caused by hypoglycaemia as a result of poorly controlled diabetes or insulinomas, ${ }^{7}$ although these tumours are relatively rare. Hyperparathyroidism can also present with a mixed picture of fluctuating symptoms associated with diurnal variation but on a background of gradual decline. ${ }^{8}$ Common drugs that can cause delirium include anticholinergic drugs, anticonvulsants, antidepressants, antipsychotics, antiparkinsonian agents, opioid analgesics, and sedatives, in addition to multipharmacy. ${ }^{9}$ 
The most likely cause of this patient's protracted symptoms of forgetfulness is a dementia syndrome. Dementia is characterised by a progressive decline that causes memory loss and impairment in at least one other cognitive function, such as recognition, language, speech, or higher executive functions that affect activities of daily living. ${ }^{10}$ The prevalence of the various subtypes of dementia is unclear, but nearly two thirds $(62 \%)$ of patients with dementia in the United Kingdom are thought to have Alzheimer's disease and around a quarter (27\%) to have vascular dementia or mixed Alzheimer's disease and vascular dementia pathology.$^{11}$ Most of the remainder (around $8 \%$ ) have dementia with Lewy bodies, frontotemporal, Parkinson's disease dementia, and alcoholic dementia in decreasing frequency. ${ }^{11}$

Our patient's symptoms were most typical of dementia with Lewy bodies-her cognitive symptoms fluctuated, often on an hourly basis, and included visual hallucinations. She also had supporting features of frequent falls and rapid eye movement sleep behaviour disorder (characterised by complex motor activity during rapid eye movement sleep). ${ }^{12}{ }^{13}$ Dementia with Lewy bodies - first described in 1990-has symptoms similar to both Alzheimer's disease and Parkinson's disease, but the parkinsonian motor features present after the cognitive symptoms. ${ }^{14}$ Dementia with Lewy bodies, idiopathic Parkinson's disease, and Parkinson's disease dementia are different but overlapping phenotypes, and it is unclear whether they are distinct but convergent clinical syndromes or divergent common neurobiological pathologies. Memory impairment occurs later in dementia with Lewy bodies and is less pronounced than in Alzheimer's dementia, although both dementia subtypes seem to have a similar rate of progression. ${ }^{15}$ It is important to distinguish between these two types of dementia because the clinical progression can be different and patients with dementia with Lewy bodies are exquisitely sensitive to neuroleptic drugs, with $50-80 \%$ having side effects such as confusion, sedation, rigidity, and most importantly increased mortality. ${ }^{16} 17$

\section{What investigations would you do? Short answer}

No simple blood test is available to screen for dementia. Blood tests are important in helping to rule out delirium but are also used in the investigation of dementia-to look for reversible causes of dementia—and specialist memory clinics should undertake full neuropsychological profiling along with appropriate brain imaging.

\section{Long answer}

Investigations appropriate to primary care should include a screen for risk factors such as diabetes and

hypercholesterolaemia that might contribute to a vascular component of dementia. Commonly requested blood tests include a full blood count; renal and liver profile; thyroid function; and concentrations of calcium, vitamin $\mathrm{B}_{12}$, folate, fasting glucose, and cholesterol. Urinalysis should be performed to screen for infection as a cause of delirium.

Electrocardiography and chest radiography are also advised by the UK guidelines. ${ }^{1}$ In addition, if the history or physical examination point to specific risk factors, request HIV, syphilis, and Borrelia serology blood tests.

Several cognitive screening tests are available for use in primary care. The most well known is the MMSE. ${ }^{18}$ However, this test is difficult to administer in the short time allowed for general practice consultations and it may show cultural and language bias. ${ }^{19}$ Newer screening tests have been developed and validated for use in the community setting. They have been shown to be as robust as the MMSE but can be administered in five minutes or less; these tests include the general practitioner assessment of cognition (GPCOG), mini-cog, and memory impairment screen, with sensitivity varying from $69 \%$ to $80 \%$ and specificity from $86 \%$ to $96 \% .^{20}$ Another screening tool, the 6 item cognitive impairment test (6CIT) has also been shown to be at least equivocal to the MMSE in selected secondary care populations. ${ }^{21}$ GPCOG (www.gpcog.com.au/prep.php) and 6CIT (www. falklandsurgery.co.uk/6cit/index.asp) are available electronically for ease of administration in the surgery. Most cognitive screening tools are developed for typical symptoms of Alzheimer's disease, and patients with dementia with Lewy bodies may fall within the normal range. These screening tests are used to help decide on the need for referral to a specialist memory clinic for more thorough cognitive and neuropsychological assessment, including structural neuroimaging. When a diagnosis of dementia is suspected, this possibility must be discussed candidly and sensitively with the patient and carer to gauge their expectations and wishes before making a referral to specialist services. ${ }^{22}$

The battery of specific tests included in neuropsychological testing varies by clinic and also depends on the type of dementia and cognitive and functional disturbances that are suspected. Patients with dementia with Lewy bodies usually show prominent early impairment in attention, visuospatial skills, and visuoconstructive skills - as detected by clock drawing and figure copying tests-whereas those with Alzheimer's dementia show greater impairments in memory. ${ }^{12}$

Structural and physiological neuroimaging are increasingly being used to aid earlier distinction between dementia with Lewy bodies and Alzheimer's disease. Computed tomography and magnetic resonance imaging tend to show more advanced hippocampal and mediotemporal lobe atrophy in Alzheimer's disease than in dementia with Lewy bodies, but this is not specific, especially in early disease. ${ }^{13}$ The dopaminergic system can be physiologically imaged using single photon emission computed tomography (SPECT) and positron emission tomography (PET) and the ligands FP-CIT labelled with iodine-123 (N-fluropropyl-2bcarbomethoxy-3b-4- ${ }^{123}$ I-iodophenyl tropane) and dopa labelled with fluorine- $18\left({ }^{18} \mathrm{~F}\right.$-flurodopa), respectively. Lewy bodies cause disruption of the presynaptic dopaminergic neurones in the corpus striata, as shown by reduced ligand uptake in these areas with SPECT. Ongoing multicentre trials are assessing the concordance between clinical diagnoses, SPECT neuroimaging diagnoses, and postmortem diagnoses for dementia with Lewy bodies. ${ }^{23-25}$ PET is used much less often in clinical practice, but group studies have shown good discrimination between dementia with Lewy bodies and Alzheimer's disease, with occipital hypoperfusion being seen in dementia with Lewy bodies ${ }^{26-29}$; one group has suggested that occipital hypoperfusion may be responsible for the visual hallucinations in this condition. ${ }^{29}$ Guidelines now reflect the use of neuroimaging in early diagnosis and it is no longer necessary to have two core clinical features of dementia with Lewy bodies, but instead one core clinical feature with supportive neuroimaging can be used to make a probable diagnosis (box).

Some clinics also perform analysis of cerebrospinal fluid to look for Creutzfeldt-Jakob disease and to search for specific tau and amyloid $\beta$ proteins seen in Alzheimer's disease. More recently, cardiac imaging with ${ }^{123} \mathrm{I}$ labelled meta-iodobenzylguanidine ( ${ }^{123} \mathrm{I}-\mathrm{MIBG}$ ) has shown a reduction in autonomic postganglionic sympathetic fibres in the cardiac plexus in Lewy body degenerative diseases, such as dementia with Lewy bodies and idiopathic Parkinson's disease. This test 


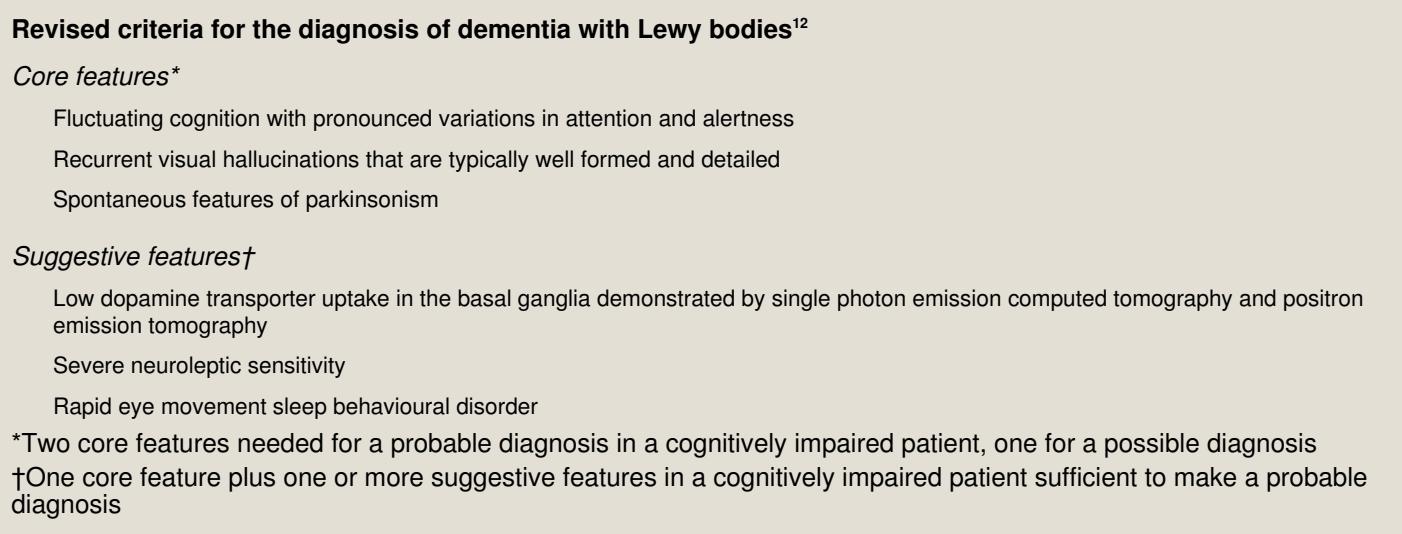

has been used to discriminate between Alzheimer's disease and dementia with Lewy bodies in people with moderate dementia. ${ }^{30-32}$ These changes may support the early diagnosis of dementia with Lewy bodies, but they lack specificity because reduced uptake on MIBG scans is also seen in cardiovascular diseases that are common in this typically older age group, such as ischaemic heart disease, cardiomyopathy, and their risk factor, diabetes. $^{13}$

A postmortem brain biopsy is needed for a definitive diagnosis, with cortical or brainstem Lewy body pathology being essential criteria. ${ }^{33}$ Other changes are also common, such as Alzheimer's pathology and spongiform pathology.$^{33}$ Lewy bodies are accumulations of $\alpha$ synuclein protein that form strongly eosinophilic intracytoplasmic neuronal inclusions. As with Alzheimer's disease, these protein accumulations are thought to be associated with the clinical symptoms of Lewy body diseases through neuronal cell loss and disruption of normal brain architecture.

\section{How should this patient be managed? Short answer}

After baseline investigations in primary care, we referred our patient to local specialist memory services for neuroimaging, neuropsychological assessment, and consideration of pharmacotherapy. A thorough assessment of current needs and future goals should be made with the patient and carers, and appropriate referral should be made to members of the multidisciplinary care team, with planned regular review.

\section{Long answer}

UK dementia clinical guidelines from 2006 describe overarching priorities of care for patients with dementia that should guide decision making between patients, carers, and health and social care practitioners. ${ }^{1}$ The recommendations include non-discrimination; seeking valid consent using the provisions of the Mental Capacity Act $2005^{34}$; assessing and providing for the needs of carers; integrating health and social care; providing specialist memory services for all people with a possible diagnosis of dementia; and comprehensively assessing and managing non-cognitive and behavioural symptoms that can distress patients and carers. The Department of Health built on this guidance with its National Dementia Strategy (2009) ${ }^{35}$ and most recently with its publication of risk guidance for dementia (2010) to maintain function and to promote and support personal freedoms and independent living in people with dementia. ${ }^{36}$ Patients and carers should have early signposting to support groups such as the Alzheimer's Society (http://alzheimers.org. uk/), Lewy Body Dementia Association (www.lbda.org/), the Lewy Body Society (www.lewybody.co.uk/), Dementia UK (www.dementiauk.org/), and MIND. ${ }^{37}$ Carers of patients with dementia will need support-such as psychological services, support groups, and respite care- to help them in their role. Planning should be encouraged, particularly with regard to advocacy, decisions on medical treatment that may include advanced statements; living arrangements; and finances, including appointing a lasting power of attorney. The guiding theme of all management decisions taken with the patient and carers should be one of supporting and maintaining the patient's independence and quality of life.

Specialist memory services are primarily responsible for balancing the treatment of the many facets of this clinical syndrome - cognitive, behavioural, psychiatric, mood related, and extrapyramidal. First line drugs for cognitive and psychiatric symptoms are the cholinesterase inhibitors-donepezil, galantamine, and rivastigmine-which rarely exacerbate the associated extrapyramidal symptoms; rivastigmine has the most supportive data for this indication. ${ }^{18}{ }^{38-40}$ Treat parkinsonian motor features with dopaminergic agents, commonly carbidopa and levodopa, and titrate them to the optimum dose to balance any improvement in motor function against possible worsening of cognitive and psychiatric symptoms. ${ }^{38}$ Depression is common in dementia with Lewy bodies and despite the lack of clinical trials assessing the efficacy of antidepressants in this group, selective serotonin reuptake inhibitors are advised as first line agents, with avoidance of tricyclic antidepressants in case of antimuscarinic side effects. ${ }^{3841} 42$ The management of psychotic symptoms, such as visual hallucinations and delusions that can lead to pronounced agitation, are particularly challenging. Patients with Lewy body dementia have marked neuroleptic sensitivity, with increased morbidity and mortality, ${ }^{43}{ }^{44}$ which abrogates the use of typical antipsychotics. Non-pharmacological methods should be instituted first, and only in the case of severe and recalcitrant symptoms should specialist teams consider small doses of the atypical antipsychotics; clozapine has been consistently more effective than quetiapine for this indication. ${ }^{41}$

\section{Patient outcome}

Our patient developed symptoms of depression and was followed up jointly by the local neurology and memory services and mental health teams for older people. She was given mirtazapine for depressive symptoms and the cholinesterase inhibitor, rivastigmine, for first line treatment of cognitive symptoms and visual hallucinations. Physiotherapy was started for her coexistent polyneuropathy symptoms, although frank parkinsonian motor features were mild except for syncopal attacks. Ongoing coordinated review was organised between the general practitioner and secondary care teams. 
Competing interests: All authors have completed the ICMJE uniform disclosure form at www.icmje.org/coi_disclosure.pdf (available on request from the corresponding author) and declare: no support from any organisation for the submitted work; no financial relationships with any organisations that might have an interest in the submitted work in the previous three years; no other relationships or activities that could appear to have influenced the submitted work.

Provenance and peer review: Commissioned; externally peer reviewed. Consent was obtained from the patient and her husband. The husband read the article to the patient and both were happy with its content. LP assessed the patient as having capacity at the time of reading the article to comprehend and consider its contents as pertaining to her medical history and provide both verbal and written consent for its publication.

1 National Institute for Health and Clinical Excellence. Dementia: supporting people with dementia and their carers in health and social care. 2006. www.nice.org.uk/CG42.

2 Cole MG, McCusker J, Ciampi A, Dyachenko A. An exploratory study of diagnostic criteria for delirium in older medical inpatients. J Neuropsychiatry Clin Neurosci 2007;19:151-6.

3 Inouye SK, van Dyck CH, Alessi CA, Balkin S, Siegal AP, Horwitz RI. Clarifying confusion: the confusion assessment method. A new method for detection of delirium. Ann Intern Med 1990;113:941-8.

4 Cole MG. Delerium in elderly patients. Am J Geriatr Psychiatry 2004;12:7-21

5 George J, Bleasdale S, Singleton SJ. Causes and prognosis of delirium in elderly patients admitted to a district general hospital. Age Ageing 1997;26:423-7.

6 Norman DC. Fever in the elderly. Clin Infect Dis 2000;31:148-51.

7 Brooks A, Vaidya B. An elderly woman with recurrent episodes of confusion. BMJ 2010;340:c1998.

8 Dennis M, Parker SG. Hyperthyroidism and dementia. Postgrad Med J 1997;73:755-7.

9 Saxena S, Lawley D. Delirium in the elderly: a clinical review. Postgrad Med J 2009;85:405-13.

10 American Psychiatric Association. Diagnostic and statistical manual of mental disorders DSM-IV. APA, 1994.

11 Alzheimer's Society. Full dementia UK report. 2007. http://alzheimers.org.uk/site/scripts/ download_info.php?fileID $=2$.

12 Geser F, Wenning GK, Poewe W, McKeith I. How to diagnose dementia with Lewy bodies: state of the art. Mov Disord 2005;20(suppl 12):S11-20.

13 Kemp PM, Holmes C. Imaging in dementia with Lewy bodies: a review. Nucl Med Commun 2007;28:511-9

14 Perry RH, Irving D, Blessed G, Fairbairn A, Perry EK. Senile dementia of Lewy body type: a clinically and neuropathologically distinct form of Lewy body dementia in the elderly. $J$ Neurol Sci 1990;95:119-39.

15 Alzheimer's Society. What is dementia with Lewy bodies? 2010. http://alzheimers.org.uk site/scripts/documents.php?categorylD=200137.

16 McKeith I, Fairbairn A, Perry R, Thompson P, Perry E. Neuroleptic sensitivity in patients with senile dementia of Lewy body type. BMJ 1992:305:673-8.

17 McKeith IG, Mosimann UP. Dementia with Lewy bodies and Parkinson's disease. Parkinsonism Relat Disord 2004;10(suppl 1):S15-8.

18 Aarsland D, Mosimann UP, McKeith IG. Role of cholinesterase inhibitors in Parkinson's disease and dementia with Lewy bodies. J Geriatr Psychiatry Neurol 2004;17:164-71.

19 Black SA, Espino DV, Mahurin R, Lichtenstein MJ, Hazuda HP, Fabrizio D, et al. The influence of noncognitive factors on the mini-mental state examination in older Mexican-Americans: findings from the hispanic EPESE. J Clin Epidemio 1999:52:1095-102

20 Brodaty H, Low LF, Gibson L, Burns K. What is the best dementia screening instrument for general practitioners to use? Am J Geriatr Psychiatry 2006;14:391-400

21 Brooke P, Bullock R. Validation of a 6 item cognitive impairment test with a view to primary care usage. Int J Geriatr Psychiatry 1999;14:936-40.
22 Iliffe S, Robinson L, Brayne C, Goodman C, Rait G, Manthorpe J, et al. Primary care and dementia: 1. diagnosis, screening and disclosure Int J Geriatr Psychiatry 2009:24:895-901.

23 McKeith IG, Perry EK, Perry RH. Report of the second dementia with Lewy body international workshop: diagnosis and treatment. Consortium on Dementia with Lewy Bodies. Neurology 1999;53:902-5.

24 McKeith I, O'Brien J, Walker Z, Tatsch K, Booij J, Darcourt J, et al. Sensitivity and specificity of dopaminergic transporter imaging with 123I-FP-CIT SPECT in dementia with Lewy bodies; a phase III multi-centre, prospective study Lancet Neurol 2007:6:305-13.

25 Walker Z, Jaros E, Walker RWH, Lee L, Costa DC, Livingston G, et al. Dementia with Lewy bodies: a comparison of clinical diagnosis, FP-CIT single photon emission computed tomography imaging and autopsy. J Neurol Neurosurg Psychiatry 2007;78:1176-81.

26 Ishii K, Imamwa T, Sasaki M, Yamaji S, Sakamoto S, Kitagaki H, et al. Regional cerebra glucose metabolism in dementia with Lewy bodies and Alzheimer's disease. Neurology 1998;51:125-30.

27 Minoshima S, Foster NZ, Sima AA. Alzheimer's disease versus dementia with Lewy bodies: cerebral metabolic distinction with autopsy confirmation. Ann Neurol 2001;50:358-65

28 Higuchi M, Tashiro M, Arai H, Okamura N, Hara S, Higuchi S, et al. Glucose hypometabolism and neuropathological correlates in brains of dementia with Lewy bodies. Exp Neurol 2000;162:247-56.

29 Imamura T, Ishii K, Hirono N, Hashimoto M, Tanimukai S, Kazuai H, et al. Visua hallucinations and regional cerebral metabolism in dementia with Lewy bodies. Neuroreport 1999;10:1903-7.

30 Watanabe H, Leda T, Katayama T, Takeda A, Aiba I, Doyu M, et al. Cardiac 123I-meta-iodobenzylguanidine (MIBG) uptake in dementia with Lewy bodies: comparison with Alzheimer's disease. J Neurol Neurosurg Psychiatry 2001;70:781-3.

31 Yoshita M, Taki J, Yamada M. A clinical role for [123I]MIBG myocardial scintigraphy in the distinction between dementia of the Alzheimer's type and dementia with Lewy bodies. $J$ Neurol Neurosurg Psychiatry 2001;71:583-8.

32 Oide T, Tokuda T, Momose M, Oguchi K, Nakamura A, Ohara S, et al. Usefulness of [1231]metaiodobenzylguanidine ([123]]MIBG) myocardial scintigraphy in differentiating between Alzheimer's disease and dementia with Lewy bodies. Int Med 2003;42:686-90

33 McKeith IG, Galasko D, Kosaka K, Perry EK, Dickson DW, Hansen LA, et al. Consensus guidelines for the clinical and pathologic diagnosis of dementia with Lewy bodies (DLB): report of the consortium on DLB international workshop. Neurology 1996;47:1113-24.

34 National Archives. Mental Capacity Act 2005. www.legislation.gov.uk/ukpga/2005/9/ contents.

35 Department of Health. Living well with dementia: a national dementia strategy. 2009 (updated 2011). www.dh.gov.uk/en/SocialCare/NationalDementiaStrategy/index.htm.

36 Department of Health. Nothing ventured, nothing gained: risk guidance for people with dementia. 2010. www.dh.gov.uk/en/Publicationsandstatistics/Publications/ PublicationsPolicyAndGuidance/DH_121492.

37 MIND. Understanding dementia. 2008. www.mind.org.uk/help/diagnoses_and_conditions/ dementia.

38 McKeith IG, Dickson DW, Lowe J, Emre M, O'Brien JT, Feldman H, et al. Diagnosis and management of dementia with Lewy bodies. Third report of the DLB consortium. Neurology 2005;65:1863-72

39 Fischer C, Bozanovic R, Atkins JH, Rourke SB. Treatment of delusions in dementia with Lewy bodies: response to pharmacotherapy. Dement Geriatr Cogn Disord 2007;23:307-11.

40 McKeith I, Del Ser T, Spano P, Emre M, Wesnes K, Anand R, et al. Efficacy of rivastigmin in dementia with Lewy bodies: a randomized, double-blind, placebo-controlled international study. Lancet 2000;356:2031-6.

41 Poewe W. Treatment of dementia with Lewy bodies and Parkinson's disease dementia. Mov Disord 2005;20(suppl 12):S77-82.

42 Burn DJ. Beyond the iron mask: towards better recognition and treatment of depression associated with Parkinson's disease. Mov Disord 2002;17:445-54.

43 McKeith I, Fairbairn A, Perry R, Thompson P, Perry E. Neuroleptic sensitivity in patients with senile dementia of Lewy body type. BMJ 1992;305:6783-6.

44 Swanberg MM, Cummings JL. Benefit-risk considerations in the treatment of dementia with Lewy bodies. Drug Safety 2002;25:511-23.

Cite this as: BMJ 2011;343:d7412

@ B BMJ Publishing Group Ltd 2011 